\title{
Related Concepts and Basic Theory on Government Micro Blog Management
}

\author{
Yuqiang Yang ${ }^{1, \mathrm{a}}$, Baodong $\mathrm{Yu}^{1, \mathrm{~b}}$, Jiawei Zhao ${ }^{1, \mathrm{c}}$, Houhua Shen ${ }^{2, \mathrm{~d}}$ \\ ${ }^{1}$ College of Information Science and Technology, Bohai University, Jinzhou, 121013, China \\ ${ }^{2}$ College of Engineering, Bohai University, Jinzhou, 121013, China \\ ayyq8369@163.com, b589724756@qq.com, 'c17257841@qq.com, d'shenhouhuashh@126.com
}

Keywords: government affairs; micro blog management; related concepts; basic theory

\begin{abstract}
China is trying to build a service-oriented government right now, puts forward higher requirements for public management, can be good use of modern media tools in the field of public management. Government micro blog is a new means of electronic micro blog, has a natural advantage in the implementation of public management process, is an effective means of innovation in public management mode and information management. This paper researches the relate concepts and basic theory of government micro blog management. Relate concepts are mainly research in the micro blog, government micro blog and government micro management; the basic theory is mainly research in the two levels of communication theory, two-way symmetric theory, information communication theory and new public service theory. The research of this paper is the preliminary work of the government micro blog management, which lays a foundation for further research.
\end{abstract}

\section{Introduction}

Micro blog has become an important social media after the news website, forum, blog, become an important source of public opinion. Each government agencies and public service personnel have opened the government micro blog, as a channel for information dissemination, understand the way the social situation of public opinion, the platform for the public and the public to interact with the public. Our country governmental micro blog has covered the all the provincial administrative region, and extended to all areas of government agencies, such as municipal administration, business, culture, education, sports, quality inspection and other, which the government functional departments of the public security, the communist youth league, tourism, industry and commerce, taxation, transportation, judicial have obvious advantage. These functional departments contact micro blog earlier, micro blog information release timely, service, practical and interactive are relatively strong, more influential in the Internet users [1]. The development of government micro blog objectively exists the regional differences, the differences between different regions are also more obvious, more and more areas began to focus on speaking through the network, the use of micro blog service public. At present, the government micro blog show a rising trend in the number, coverage, micro blog quality, application level, comprehensive influence, etc. As an effective way promote social management innovation, government micro blog has received wide attention from the society, government support and public recognition. The research content of this paper is "research on management practice and development strategy of government micro blog in Liaoning province", which is the basis for the in-depth study of the subject. 


\section{Related Concepts}

Government micro blog management involves the following three related concepts:

(1) Micro Blog.

Micro blog is a kind of broadcast social network platform which is shared by the mechanism to share a brief and real time information. Micro blog based on user relationship information sharing, communication and access. Users can through the WEB, WAP and other clients to set up individual communities, use 140 word text update information, and achieve real-time sharing. Micro blog's attention mechanism is divided into two kinds of one-way and two-way. Micro blog as a platform of share and exchange, it pays more attention to the timeliness and randomness. Micro blog can express thought and the latest dynamic every moment, The blog is more emphasis on combing their own see, smell, the sense in a period of time.

\section{(2) Government Micro Blog.}

Government micro blog, is the representative of the government agencies and officials, because of public affairs and set the micro blog. Used to collect opinions, listen to public opinion, publish information, and serve the public's official network interactive platform. The main purpose is to through the positive interaction with the public, to build a society of politics, politics, politics of network communication model and platform [2]. In essence, the government micro blog is the government through the use of new information technology, with the positive impact of the Internet to create a service to the people of the way, more timely and effective way to promote the government's daily management, improve government work efficiency. It bear for the propaganda of the government's ruling ideas and social governance ideas, as well as the record of the development of government information and other missions on the inside, bear a public event and public opinion released and meet the public's right to know, the right of supervision, establish a good image of the government, enhance government's social reputation and the construction of harmonious society obligation on foreign.

(3) Government Micro Blog Management.

Government micro blog management, refers to the party and government agencies on government micro blog and related things of the management activities, so that government micro blog can better play the role in social management, so as to better realize the functions of government to provide public services. Government as a public service provider, government micro blog to provide services more convenient way. However, in order to avoid the problem of government micro blog in the social management, should be in the early days of government micro blog to carry out effective management. On the one hand, regulate the content, functions and operating mechanism of government affairs, on the other hand, appropriately control the role of government micro blog, prevent the excessive concentration of power to become party and government groups to harm society. So the government should be appropriate to the management of government micro blog.

\section{Basic Theory}

Theory is a reflection of the inherent essence and the inevitable law of the thing, is the concept or principle that is related to the actual deduction in a certain field. The scientific theory is the scientific knowledge of the system, is a relatively correct cognition about the essence and regularity of objective things, is a knowledge system which is expressed by a series of concepts, judgment and reasoning. The management and research of government micro blog, needs the guidance of the basic theory.

\section{(1) Two-step Flow of Communication Theory}

A study of F. Lazarsfeld Paul, a pioneer in the study of communication studies, was found in 1940 ,in the presidential election, the change of the political tendency of the voters is seldom influenced by the mass media, and it is the key to the formation and transformation of political attitude. Information and ideas are usually the first from a source of information, through the mass 
media to reach the so-called "leader Opinion"; and then through the "opinion leader" to spread the information to the general public. As shown in Fig. 1.

As the first stage, the former is the process of information transmission, the latter is the second stage, which is the diffusion of human influence. This is the famous "two step -flow hypothesis". It enables people to realize the different roles and functions of mass media channels and human communication channels in people's information acquisition and decision making. In the diffusion of innovation, the two stage model have great significance. The audience for the innovation of the use of the following stages: cognition, persuasion, decision making, use and confirmation. In the interpretation of the two levels of communication, mass communication has an important role in people's cognitive stage, and the influence of interpersonal communication is more significant in persuasion and decision-making stage. Therefore, although in communication technology, the audience at the same time both in the dissemination of information coverage, and clings in the diffusion network of interpersonal communication, but both for the audience by the impact of new technology is different. There is a difference in the process of using the above, but also has a more complex communication behavior.

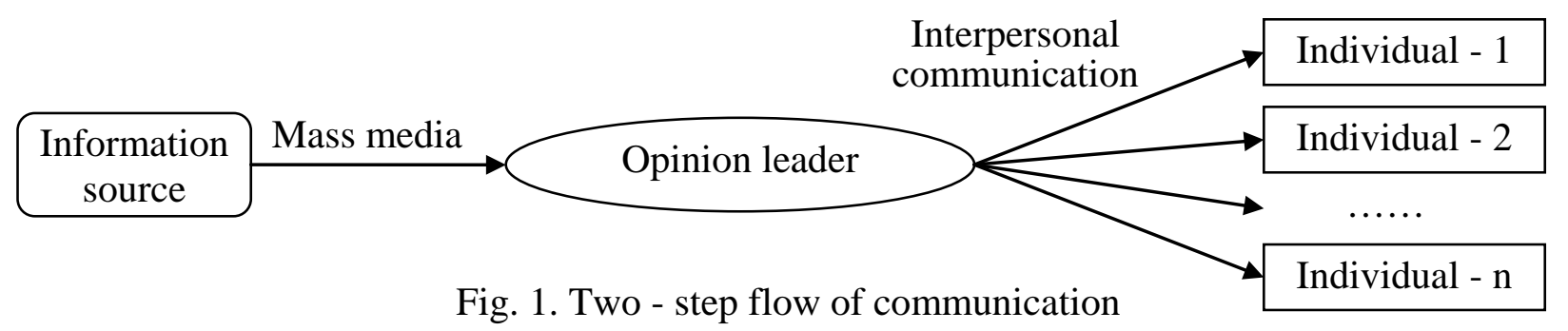

\section{(2) Two - way Symmetry Theory}

The theory of Bi direction symmetry is an important theory in public relations, which is proposed by American scholar Cutlip M. According to the theory of bi directional symmetry, the public relations should spread the ideas and information to the public. On the other hand, the public's ideas and information should be transmitted to the organization. The aim is to form a harmonious relationship between the organization and the public. This kind of public relations model, in the public relations goal, the organization and the public interest in the same important position, in the method to adhere to the organization and the public between the two-way communication and communication. As shown in Fig. 2.

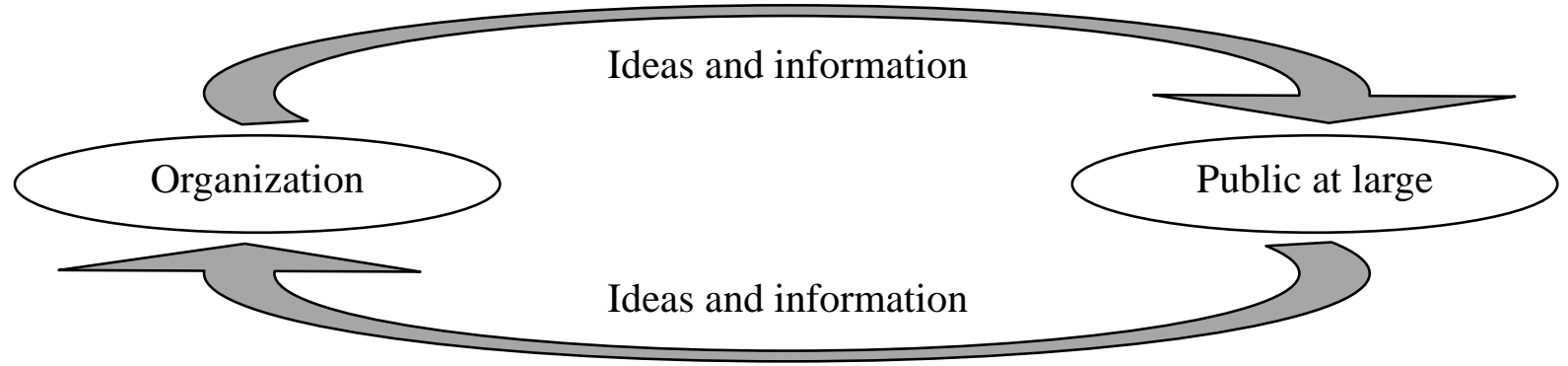

Fig. 2. Two - way symmetry theory

The government micro blog provides a new platform for government information dissemination, and the original "one-way communication" is changed to more effective "two-way communication". The public relations of the two way symmetry is the advanced stage of the development of the contemporary public relations, emphasizing the "two-way communication, two-way balance, public participation". Combined with the theory of two-way symmetrical communication, the government can reshape the image of public relations. First, the government uses the means of information technology to establish a platform for communication between the government and the public. It is one of the important factors to establish a good government service to use the good information technology. Secondly, the government should realize the effective government affairs open, create the new image of "sunshine government" and "transparent government". The public has the right to 
know the public information, the government must establish a feasible public information dissemination mechanism, with reasonable public relations means truly reflect the objective reality, which requires the government to public information disclosure, information sharing, information feedback; finally, in the government public relations image, the government must interact with the media to maintain good relations of cooperation.

\section{(3) Information Communication Theory}

Information communication refers to the interpretation of the transfer of information from sender to receiver process. In particular, it is the exchange of ideas, feelings, ideas and attitudes among people. It is the process of information exchange. To understand the information communication, it is necessary to pay attention to the following points: information communication is the transmission of information, if the information has not been passed, information communication, information communication, not only need to be transmitted, but also to be understood; communication is the main body of information communication between people and people [3,4]. Information communication process as shown in Fig. 3.

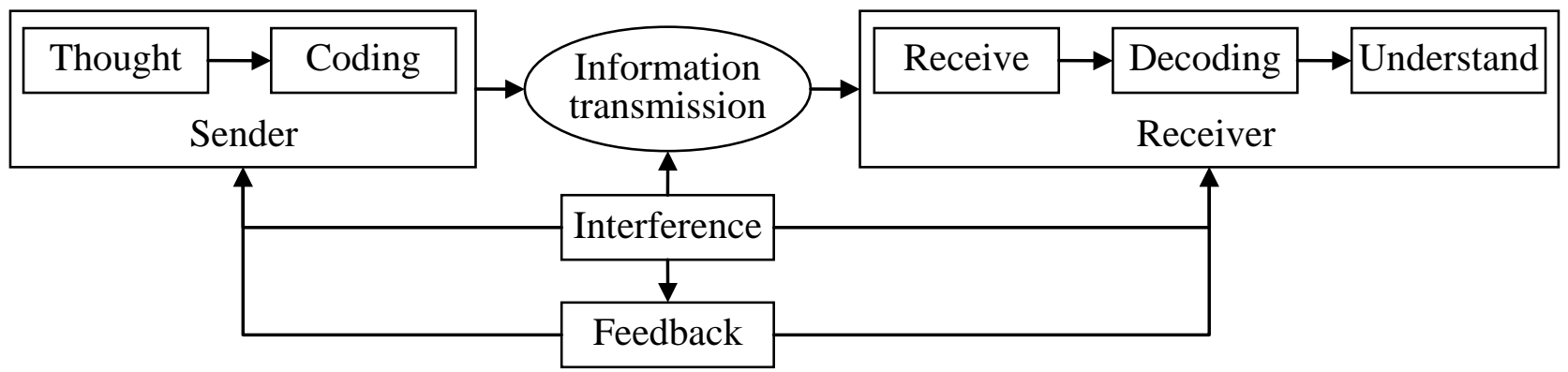

Fig. 3. Information communication process

From Fig. 3 can see, the information communication process of several steps: thinking, information sender sends out information is because some reason to want the receiver to understand certain things, so it is necessary to clearly communicate the information content; encoding, the information content is expressed as a certain or certain symbols, such as language, text and gestures, etc..Only through encoding, can the information be transmitted; the information is transmitted through a channel, and the important or complex information needs to be transmitted through a variety of channels such as conversation, telephone, mail and communication, etc. After receiving the information received by the recipient, it can be understood and studied the content and meaning of the received information; feedback, the recipient of the received or understood information back to the sender there, when necessary verify and make amendments for the sender.

The role of information communication is to enable each member of the organization to be able to do so in due time, the appropriate information, with the appropriate method, to the appropriate person, thus forming a sound and rapid effective information delivery system, in order to help achieve the organization's objectives. Information communication has the following functions: communication is the premise and foundation of the correct decision. Communication is the tool of the organization's members. Communication is the key to establish a good interpersonal relationship between the members of the organization, especially the leader and the leader.

\section{(4) New Public Service Theory}

The new public service theory is a group of public management scholars, represented by B. Denhardt Robert, a famous American public management expert, based on the new public management theory, especially for the new public management theory, the essence of the criticism of the theory of entrepreneurs, from the establishment of a new public management theory. The new public service theory believes that public managers in public administration and public policy implementation, it should be concentrated in the commitment of the civil service and to civil rights with responsibilities, priorities should neither is at the helm of the government of the ship, nor should is to paddle, but should is with obvious improvement of integration and responsiveness of the public institutions. The new public service theory is the idea and value of the administration from the perspective of market and economics, so as to establish a set of new theoretical system of 
administrative development. The theoretical foundation and core content of the new public service theory as shown in Fig. 4.

The new public service theory has the following four characteristics [5]: the core of government responsibility, the government and the public interest, the government are the representative of the public interest, the government is to follow the principle of fairness, justice, efficiency, participation, express the public interest, and promote the efficiency of government, promote the performance of government responsibility, can deal with all kinds of unexpected events timely, accurate and effective handling of administrative affairs, emphasize the effectiveness of the government's good governance, the government's responsibility is to maximize the public interest, and the good governance is to maximize the social management process.

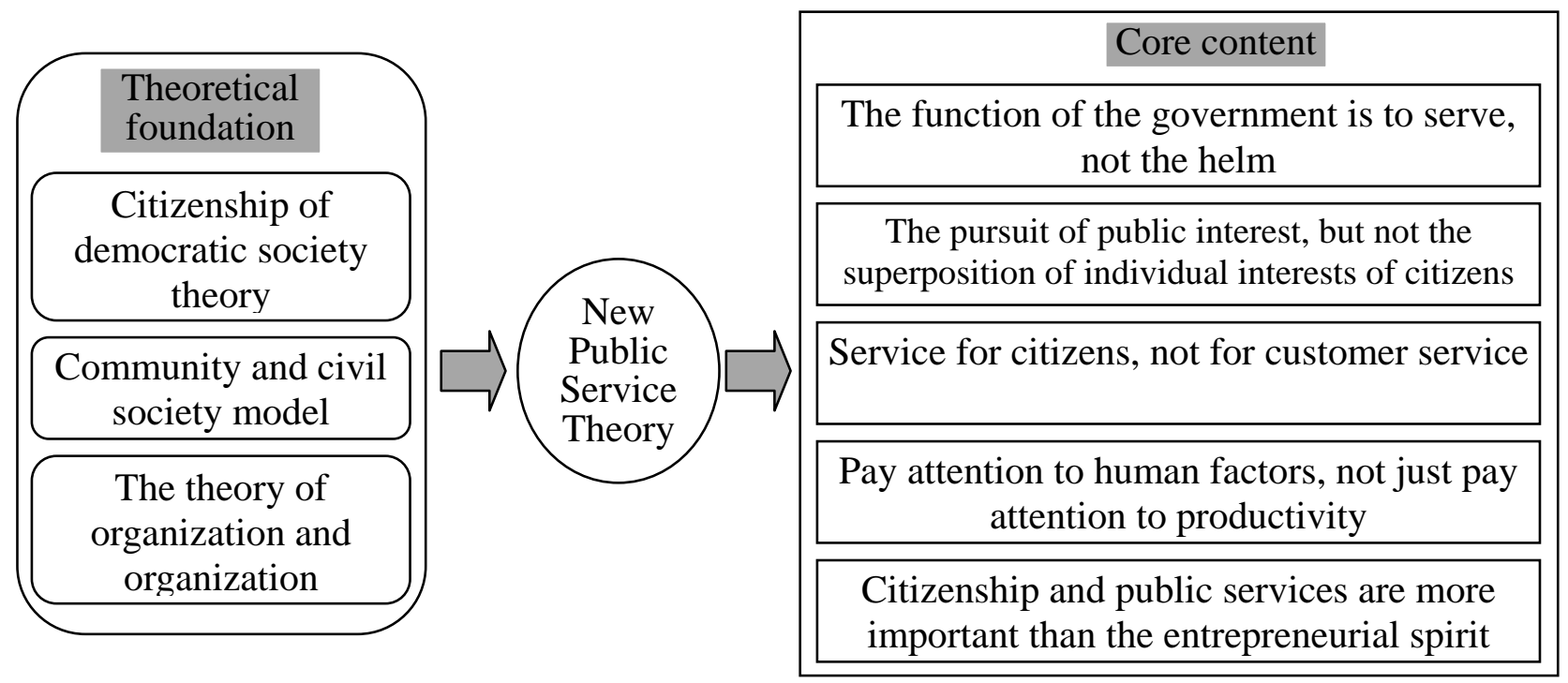

Fig. 4. New Public Service Theory

\section{Conclusion}

Government micro blog is a product of the combination of the process of democratic politics and media technology. It is a new form of government communication in the new media age. It reflects the government's adaptation to the citizen in the channel. It is the inevitable choice for the government to spread the means of communication, and it also promotes the diversification of political communication. As a means of government information disclosure, government micro blog further enhance the transparency of government work, promote the government agencies and citizens or other social groups, good communication, for the protection of citizens' right to know and express the right to have a positive meaning, but also conducive to the government to improve the level [6].Using the research results of this paper, we can conduct a more in-depth study of government micro blog, through the smooth communication channels and strengthen the regulatory system, the government micro blog development into a new mainstream political communication platform.

\section{Acknowledgement}

This work is supported by social science fund project of Liaoning province (L13BGL013): Research on management practice and development strategy of government microblogging in Liaoning province. 


\section{References}

[1] W. W. Zhang, "Research on the Communication Effect of Government Micro-blog during the Social Transitional Period of our country," Master's degree of Jiangxi university of finance and economics, 2013.

[2] J. M. Cao, "Effect on government micro blog in the construction of public relations," The Press, vol. 60, no. 11, pp. 103-105, 2015.

[3] Q. Ren, "Rebuilding credibility on non profit organization based on information communication theory," Chinese youth, vol. 27, no. 13, pp. 125-126, 2015.

[4] L. Zhang, J. Yang, "On the application of collusion theory in the book purchases of academic libraries," Journal of Academic Library and Information Science, vol. 24, no. 1, pp. 57-58, 2006.

[5] D. Tu, "The study of Hangzhou Public Bicycle System under New Public Service Theory," Master's degree of East China University of Political Science and Law, 2014.

[6] L. M. Xu, "Research on communication effect of government micro - blog in public space: Shanghai government micro blog as an example," Master's degree of Master's degree of Shanghai jiaotong university, 2011. 